\title{
PENGEMBANGAN POTENSI WISATA AGRO DI KAWASAN CONDET KELURAHAN BALEKAMBANG JAKARTA TIMUR
}

\author{
Development Of Agrotourism Potential In Condet Kelurahan Balekambang \\ East Jakarta
}

\author{
Nahri Nurul Azriati, Devi Kausar \\ Fakultas Pariwisata, Universitas Pancasila \\ Srengseng Sawah, Jagakarsa Jakarta Selatan, 12640 Indonesia
}

\begin{abstract}
Jakarta as tourist destinations in Indonesia to implement various types of travel include cultural, historical and ecotourism. For examples of nature tourism in Jakarta is the issue of potential development of the Ciliwung River as a nature-based tourist destination. One segment which is a conservation area in the Watershed is Fruit of Condet, East Jakarta. Lahan Buah Condet is the only farm remaining pockets of the vast Condet set at DCI Jakarta Governor Decree No.DIV-1511/E/74. Potential tread such as endemic plants typical namely Salak and Duku Condet. Their Jakarta Governor Decree No. 6462016 to further accelerate the implementation of the settlement and development of Lahan Buah Condet as a tourist destination as well as agrotourism area in East Jakarta. Problems in development of agrotourism is limited plantations, easily flooded, access to the plantations in the housing area residents and utilization of spatial patterns that are less well maintained, it is feared to cause damage to plantations. This research used qualitative method. By combining variable of agrotourism, conservation, and considering the potential of the land, found a solution how the concept of agrotourism in the form attractions, accessibilities, amenities, ancillary and institutions in Lahan Buah Condet can be suitable with the concept of consideration factors for agro tourism development.
\end{abstract}

Keywords : Agrotourism, Tourism Destinations, Tourism Development 


\section{Pendahuluan}

Jakarta sebagai Daerah Khusus Ibukota yang terus mengalami perubahan yang signifikan dan perkembangan pembangunan pada berbagai aspek, memiliki daerahdaerah dengan potensi yang menonjol untuk ditingkatkan dan dilestarikan. Salah satu daerah di Jakarta yang perlu diperhatikan potensinya adalah Condet. Pada tahun 1975 Gubernur DKI Jakarta telah mengeluarkan SK Gubernur No. D.I-70903/a/30/1975 sebagai Penegasan Penetapan Kelurahan di Condet yaitu Kelurahan Kampung Tengah, Kelurahan Balekambang, Kelurahan Batu Ampar, serta Kecamatan Kramat Jati Wilayah Jakarta Timur sebagai daerah Cagar Budaya buah-buahan. Sejalan dengan perkembangan dan pembangunan kota Jakarta yang cukup pesat, dimana kebutuhan lahan atau tanah untuk pembangunan prasarana seperti ruang terbuka hijau atau taman kota, jalan raya, fasilitas sosial, fasilitas ekonomi bahkan perumahan terus meningkat di lingkungan Condet dan terus menerus meningkat. Berbagai upaya pada masa periode kepemimpinan Gubernur Ali Sadikin yang lalu telah dilakukan oleh pemerintah DKI Jakarta dalam mempertahankan kelestarian Kawasan Condet ini.

Sebagai kawasan yang mungkin hampir hilang eksistensinya dan mulai mengalami alih fungsi, Condet masih memiliki aset menarik untuk ditingkatkan potensinya berupa keunggulan floranya yaitu buah Salak dan Dukuh khas Condet dan berbagai macam tumbuhan lainnya. Kawasan Condet memiliki keunggulan flora yang sangat berpeluang untuk dibudidayakan.
Menyikapi hal itu, pelestarian dan konservasi lingkungan sangat diperlukan agar, potensi lahan buah Condet tetap terjaga dan dapat bermanfaat di masa mendatang. Pengembangan potensi wisata dirasa perlu untuk membantu melestarikan kawasan Condet sebagai salah satu destinasi wisata yang berpotensi di bidang wisata agro. Faktor pertimbangan pengembangan kawasan wisata agro menurut Syamsu, (2001) untuk menjadikan suatu kawasan menjadi daya tarik wisata yaitu faktor pertimbangan kelangkaan (Scarcity), faktor pertimbangan kealamiahan (Naturalism), faktor pertimbangan keunikan (Uniqueness), faktor pertimbangan pemberdayaan masyarakat

(Community Empowerment), faktor pertimbangan optimalisasi lahan (Area Optimalisation), faktor pertimbangan keadilan, dan faktor pertimbangan pemerataan.

\section{Metode Penelitian}

Penelitian ini dilaksanakan di Lahan Buah Condet yang berada di dalam kawasan Komunitas Ciliwung Condet yang terletak di Daerah Condet, kelurahan Balekambang, Kecamatan Kramat jati, wilayah Adminsitrasi Jakarta Timur propinsi DKI Jakarta.Waktu penelitian dilaksanakan pada bulan Maret sampai Agustus 2017. Desain penelitian yang digunakan adalah penelitian kualitatif. Sumber data pada penelitian ini adalah informan dan kawasan Condet. Informan merupakan sumber data dari data yang dihimpun dengan cara melakukan wawancara mendalam. Sedangkan kawasan merupakan sumber data yang akan dihimpun melalui observasi dan dokumentasi. 
Definisi operasional variabel yang digunakan yaitu dengan cara menggabungkan dua teori menurut Inskeep, (1999) dan teori menurut Syamsu, (2001). Variabel menurut Inskeep terdiri dari : Attractions (atraksi), accesbilities (aksesbilitas), amenities (amenitas), ancillary (fasilitas pendukung), dan kelembagaan. Sedangkan variabel menurut teori dari Syamsu yaitu terdiri dari tujuh faktor pertimbangan yaitu pertimbangan kelangkaan (scarcity), pertimbangan kealamiahan (naturalism), pertimbangan keunikan (uniqueness), pertimbangan pemberdayaan masyarakat (community empowerment), pertimbangan optimalisasi lahan (area optimalisation), pertimbangan keadilan, dan pertimbangan pemerataan.

Karena variabel yang dikemukakan Inskeep (1999) adalah mutlak untuk pengembangan semua destinasi, sedangkan faktor pertimbangan menurut Syamsu (2001) dapat diterapkan dalam pengembangan destinasi wisata agro, maka faktorfaktor pertimbangan tersebut dapat diaplikasikan sebagai karakter dari komponen pengembangan destinasi menurut Inskeep (1999). Hal ini dilakukan untuk membedakan karakteristik wisata agro dibanding wisata lainnya. Analisis dalam penelitian ini dilakukan dengan cara wawancara yang dilakukan kepada tiga pihak yaitu pemerintah, pengelola, dan masyarakat setempat. Kegiatan ini dilakukan untuk mengetahui pandangan pihak-pihak terkait mengenai pengembangan potensi wisata agro di kawasan Condet Balekambang khususnya untuk pariwisata kedepannya.
Wawancara dilakukan beberapa kali pada bulan Juli dan Agustus 2017 dengan jumlah informan sebanyak 4 orang yang terdiri dari

\begin{tabular}{|l|l|l|}
\hline No. & Nama & Jabatan \\
\hline 1. & Benar & Sekretaris Kelurahan \\
& $\begin{array}{l}\text { Sigalingging } \\
\text { S.Sos }\end{array}$ & \\
\hline
\end{tabular}

\begin{tabular}{|l|l|l|}
\hline No. & Nama & Jabatan \\
\hline 2. & Abdul Kodir & Ketua \\
& & Komunitas \\
& & Ciliwung \\
& & Condet \\
\hline
\end{tabular}

\begin{tabular}{|l|l|l|}
\hline No. & Nama & Pekerjaan \\
\hline 3. & Nunung & $\begin{array}{l}\text { Ketua RT } \\
04\end{array}$ \\
\hline 4. & Mamat & $\begin{array}{l}\text { Tokoh } \\
\text { Masyarakat }\end{array}$ \\
\hline
\end{tabular}

Analisa informasi yang dilakukan peneliti dengan teknik analisis data yang dikembangkan oleh Miler dan Huberman. Pada prinsip analisis data (informasi) kualitatif dilakukan bersamaan dengan proses pengumpulan data. Yang dikemukakan oleh Miler dan Huberman dalam Baswori dan Suwandi, (2008:209) mencakup tiga kegiatan yang bersamaan yaitu reduksi data, Penyajian data, dan Penarikan kesimpulan. ). Menurut Nasution, (1996: 114-118) cara yang dapat dilakukan untuk mengusahakan agar kebenaran hasil penelitian dapat dipercaya yaitu dengan validasi data menggunakan triangulasi. 


\section{Hasil dan Pembahasan}

Condet berada di satu kesatuan wilayah meliputi tiga kelurahan yang secara Administratif termasuk kedalam Kecamatan Kramat Jati di Wilayah Walikota Jakarta Timur. Secara geografis, Condet termasuk di bagian barat dari Wilayah Jakarta Timur. Sungai Ciliwung yang mengalir di sebelah barat Daerah Condet adalah batas antara Wilayah Jakarta Timur dan Jakarta Selatan. Ketiga kelurahan yang berada di Condet adalah Kelurahan Condet Balekambang, Kelurahan Condet Batu Ampar, dan Kelurahan Condet Kampung Tengah. Lokasi penelitian berada di Lahan Buah Condet yang terletak di dalam kawasan Komunitas Ciliwung Condet di jalan Munggang No.6 RT 10 RW 04 wilayah Condet Balekambang.

Keputusan Gubernur DKI Jakarta untuk menjadikan Kelurahan Balekambang ini sebagai daerah Cagar Budaya, tentunya melibatkan banyak pertimbangan yang bukan saja berpautan dengan alasan-alasan yang mendasari diambilnya keputusan tersebut. Tetapi juga berkaitan dengan berbagai macam implikasi baik bagi kepentingan Pemerintah DKI Jakarta maupun bagi kepentingan penduduk daerah itu sendiri dalam melangsungkan pola kehidupan mereka sehari-hari. Kelurahan Balekambang dipandang dari potensi keadaan alamnya, adalah keistimewaannya dalam hal tanaman buah-buahan.Daerah ini bukan saja perlu dipertahankan sebagai daerah berjalur hijau yang masih di dalam wilayah Jakarta yang sebagian besar wilayahnya telah dipadati gedung bertingkat.

\section{Hasil dan Temuan}

Kondisi Exsisting Destinasi Wisata Dalam mengetahui kondisi exsisting destinasi wisata peneliti melakukan penelitian dengan menggunakan teori dari Inskeep, (1999) dalam Sunaryo (2013) tentang kerangka pengembangan destinasi wisata. Suatu destinasi wisata mutlak mencakup komponen-komponen utama yaitu melihat dari segi komponen 4A dan kelembagaan ( Attractions, Accessbilities, Amenities, Ancillary, and institutions) serta melihat dari segi faktor pertimbangan pengembangan kawasan wisata agro menurut Syamsu (2001) yaitu mencakup faktor pertimbangan kelangkaan (Scarcity), pertimbangan kealamiahan (naturalism), pertimbangan keunikan (uniqueness), pertimbangan pemberdayaan masyarakat (community empowerment), pertimbangan optimalisasi lahan (area optimalisation), pertimbangan keadilan, dan pertimbangan pemerataan. Berdasarkan hasil observasi dan wawancara dengan responden maka didapatkan hasil :

\section{Attractions}

Atraksi tersebut adalah Lahan Buah Condet yang terletak di dalam Komunitas Ciliwung Condet. Jenis atraksi yang ditawarkan adalah keindahan pemandangan Kebun Buah Salak khas Condet dan berbagai jenis tumbuhan langka yang tidak ada di wilayah Jakarta lain. Selain itu Sungai Ciliwung dengan udara yang sejuk karena masih banyak pepohonan sehingga membuat nyaman pada saat berkunjung. Perkembangan wisata di Kelurahan Balekambang ini awalnya 
dilihat dari kegigihan para masyarakat sekitar yang ingin membuat kegiatan pendidikan tentang pengenalan keanekaragaman hayati, pendidikan tentang Budaya Betawi dan membuat lingkungannya menjadi nyaman, sejuk agar bisa dinikmati hingga anak cucu nanti. Kelangkaan yang ada di Lahan Buah Condet ini yang pastinya adalah beberapa jenis buah-buahan khas Condet yaitu Salak dan Dukuh. Selain pohon salak dan dukuh juga terdapat beberapa tanaman ekonomis yang langka yaitu pohon melinjo yang buahnya diolah menjadi emping. Condet sangat terkenal akan salak, dukuh, dan empingnya. Selain tanaman salak, melinjo dan dukuh terdapat pula beberapa tanaman yang juga terbilang cukup langka seperti Pohon Pucung, yang biji-bijiannya diolah menjadi kluwak untuk bumbu masakan tradisional Betawi yaitu sayur gabus pucung. Selain itu pohon yang sekiranya langka dan memiliki faktor keunikan (Uniqueness) yaitu pohon menteng, gandaria, pohon agam, pohon waru, dan pohon namnam. Ada juga pohon jambu air, jambu biji, durian, cempedak, rambutan nona, nangka dan masih banyak lagi yang merupakan varietas tanaman ekonomis yang ada. Selain pertimbangan kelangkaan, yang diperhatikan adalah faktor pertimbangan kealamiahan (Naturalism) yakni sifat asli dari atraksi yang belum tersentuh oleh perubahan akibat perilaku manusia.

Kealamiahan di Lahan Buah Condet yaitu karena di Lahan Buah Condet ini menerapkan sistem konsep berbasis konservasi alam, tanaman di lahan buah ini dirawat secara maksimal dan penuh kehati-hatian.

\section{Accessibility (Aksesibilitas)}

Aksesibilitas merupakan sarana infrastruktur menuju destinasi. Jalan masuk ataupun pintu masuk utama ke daerah tujuan wisata merupakan aspek penting dalam kegiatan pariwisata. Akses menuju ke Lahan Buah Condet yang terletak di Kelurahan Balekambang, sangat mudah dijangkau dan sudah cukup baik karena kawasan Condet memiliki letak lokasi yang sangat strategis baik menggunakan kendaraan pribadi seperti mobil dan sepeda motor. Ataupun jika ingin menggunakan kendaraan umum baik berupa motor (ojek), angkutan umum (angkot) dengan rute $\mathrm{T}$ (Trayek) dengan nomor T-07 jurusan CililitanCondet yang berwarna merah, bus metromini T-53 jurusan Kampung Melayu-Kampung Rambutan, maupun KRL Commuterline turun di stasiun Pasar Minggu dilanjutkan naik Ojek dari stasiun Pasar Minggu langsung menuju ke Lahan Buah Condet yang berada di Basecamp Komunitas Ciliwung Condet. Papan petunjuk arah yang menunjukan ke arah Condet juga mudah ditemukan dari arah Cililitan dan juga dari arah TB Simatupang. Kondisi jalan pun sebagian besar dalam kategori baik.

\section{Amenities (Amenitas)}

Yang tersedia memang masih standar dan belum memadai di Lahan Buah Condet ini. Namun jika dari segi pariwisata seperti dengan adanya kebun buah, serta Budaya Betawi cukup menarik pengunjung. Namun demikian lahan parkir tidak memadai, jika ada tamu rombongan yang banyak datang ke Lahan Buah Condet. 
Dengan adanya partisipasi masyarakat yaitu lahannya mereka untuk dijadikan lahan parkir sementara. Namun jika terus menerus meminjam lahan masyarakat juga tidak akan maksimal, maka pihak pengelola ingin melibatkan masalah lahan parkir kepada pemerintah, RT dan RW setempat dan juga masyarakat sekitar untuk membantu menyediakan lahan parkirnya untuk Lahan Buah Condet ini.Sehingga kedepannya lahan parkir dapat memudahkan wisatawan atau para peneliti yang datang ke lahan buah ini. Di lahan buah Condet juga tersedia toilet yang bersih. Sedangkan untuk sarana ibadah seperti musholla kurang memadai dan biasanya ibadah dilakukan di dalam basecamp (sekretariat) Komunitas Ciliwung Condet. Selain itu amenitas yang terdapat di lahan buah Condet ini misalnya pendopo Sekolah Alam Ciliwung. Pendopo biasanya digunakan ada acara atau kegiatan yang diselenggarakan di Komunitas Ciliwung Condet.

\section{Ancillary (Fasilitas Pendukung)}

Ancillary yaitu fasilitas pendukung atau disebut juga fasilitas tambahan yang harus disediakan oleh pemerintah daerah dari suatu daerah wisata, baik untuk wisatawan maupun untuk pelaku pariwisata. Lahan Buah Condet sudah didukung oleh fasilitas-fasilitas umum di luar amenitas pariwisata. Hal ini karena memang pembangunan yang dilakukan di Kawasan Condet sudah terbilang merata sehingga fasilitasfasilitas umum seperti ini sudah hampir tersedia. Di dekat jalan Kramat Jati yang letaknya tidak jauh dari Condet terdapat salah satu rumah sakit besar yang ada di Jakarta yaitu RS. POLRI S.Sukanto, di sekitar Jalan Raya Condet juga terdapat banyak gerai ATM Center dan terdapat beberapa jenis mesin ATM sesuai dengan Bank yang digunakan oleh wisatawan. Ketersediaan fasilitas pendukung yang ada dan yang dapat digunakan oleh wisatawan seperti Bank, Rumah Sakit, ketersediaan air dan sebagainya, maka dapat disimpulkan bahwa fasilitas pendukung dari Lahan Buah Condet sebagai destinasi wisata agro sudah cukup bagus karena telah tersedia dengan baik.

\section{Kelembagaan (Institutions)}

Komunitas Ciliwung Condet merupakan suatu lembaga organisasi yang menjadi pengelola di Lahan Buah Condet. Berdirinya KCC (Komunitas Ciliwung Condet) diawali dari terbentuknya Komunitas Ciliwung di Condet, dimana kelompok-kelompok tani di Kelurahan Balekambang saat itu diterpa banjir kiriman pada tahun 1996. Kelembagaan sosial di dalam Komunitas Ciliwung Condet juga erat bagi anggotanya yang sebagian berasal dari masyarakat di luar Kelurahan Balekambang. Anggota Komunitas Ciliwung Condet mengadakan pertemuan atau kegiatan yang dilakukuan oleh Komunitas Ciliwung Condet. Selain itu Komunitas Ciliwung Condet juga aktif dalam berbagai acara bertema lingkungan yang diselenggarakan oleh WKLH (Wahana Komunitas Lingkungan Hidup).

Hal ini bertujuan untuk menambah pengetahuan dan jaringan sesama komunitas penggiat lingkungan. Komunitas Ciliwung Condet juga sangat aktif dalam memberikan informasi mengenai Sungai Ciliwung 
di Blog KCC dan facebooknya. Komunitas juga sering bergabung dengan para aktivis komunitas lingkungan lainnya di dalam setiap kegiatan yang dilakukan. Komunitas Ciliwung Condet mempunyai visi dan misi yang harus dicapai dalam setiap kegiatannya. Visi ataupun tujuan dari Komunitas Ciliwung Condet adalah meningkatkan efektivitas pengelolaan Sungai melalui peningkatan kesadaran dari seluruh elemen masyarakat dengan menekankan pada perencanaan pengelolaan disertai data pendukung dan pembuatan percontohan pengelolaan yang mempertimbangkan aspek pendidikan, ekonomi dan konservasi alam. Sedangkan dalam menjalankan visi tersebut, Komunitas Ciliwung Condet juga memiliki misi untuk menjadikan kawasan Sungai Ciliwung Condet sebagai kawasan konservasi alam, wahana pendidikan alam, menjadikan kawasan Sungai Ciliwung sebagai areal wisata dan penyanggah cagar budaya, selain itu juga menjadikan kawasan Ciliwung sebagai situs keanekaragaman hayati nusantara dan terciptanya mobilitas masyarakat terhadap upaya penyelamatan lingkungan hidup yang mandiri dan berkelanjutan.

Kedudukan Komunitas Ciliwung Condet yang merupakan pusat dari Komunitas Ciliwung mempunyai beberapa anak Komunitas disepanjang aliran Sungai Ciliwung dari hulu hingga ke hilir. Sungai Ciliwung berhulu di Gunung Pangrango, Jawa Barat. Sungai ini mengalir melalui Puncak, Ciawi lalu belok ke arah utara melalui Bogor, Depok, Jakarta dan bermuara di Teluk Jakarta. Panjang Sungai Ciliwung hampir $97 \mathrm{~km}$.
Karena jarak yang cukup jauh maka Komunitas Ciliwung Condet memutuskan membuat jaringan sesama komunitas yang berpusat di Condet. Setiap anak komunitas mempunyai struktur organisasi masing-masing di dalam komunitasnya. Berikut Jaringan antar Komunitas Sepanjang Sungai Ciliwung.

\section{Kegiatan Aksi Langsung Nimbrung di Ciliwung}

Kegiatan Nimbrung di Ciliwung merupakan kegiatan kerja bakti membersihkan Sungai Ciliwung. Kegiatan ini dilakukan komunitas dalam rangka membersihkan sampah yang ada di sungai dan meminimalisir dampak dari pencemaran Sungai Ciliwung. Mengingat kondisi wilayah Sungai Ciliwung yang penuh dengan sampah sehingga membuat aliran tersumbat dan membuat banjir. Kegiatan ini bertujuan untuk menimbulkan kesadaran masyarakat akan pentingnya fungsi sungai yang bersih bagi kehidupan kita. Acara Nimbrung Ciliwung terakhir diselenggarakan pada tanggal 20 November 2015.

Strategi Pengembangan 4A +
Kelembagaan berdasarkan temuan
wawancara/observasi Berdasarkan
hasil temuan dalam kondisi exsisting
di Lahan Buah Condet diatas,
didapatkan hasil strategi yang harus
dilakukan untuk pengembangan
potensi wisata agro di Kawasan
Condet Kelurahan Balekambang
Jakarta Timur dengan
memperhatikan hasil dari temuan
wawancara dan observasi.

Strategi Pengembangan 4A + Kelembagaan berdasarkan temuan wawancara/observasi Berdasarkan hasil temuan dalam kondisi exsisting di Lahan Buah Condet diatas, didapatkan hasil strategi yang harus dilakukan untuk pengembangan potensi wisata agro di Kawasan Condet Kelurahan Balekambang Jakarta Timur dengan wawancara dan observasi. 


\section{Attractions}

Keunggulan potensi tanaman buah yang dimiliki Lahan Buah Condet saat ini baiknya lebih dipromosikan, baik dalam bentuk brosur, media sosial ataupun website, sehingga lebih memudahkan pengunjung untuk megetahui apa saja keindahan atraksi

\section{Accesbilities (Aksesibilitas)}

Rencana pengembangan kedua yang digunakan untuk strategi pengembangan Lahan Buah Condet yaitu menambah lagi kemudahan dari segi aksesibilitas.Dengan keunggulan letak kawasan Condet yang strategis, maka harus didukung oleh infrastruktur yang memadai guna untuk memudahkan akses bagi pengunjung untuk menuju ke kawasan Lahan Buah Condet ini sebagai berikut :

- Menyediakan lebih banyak armada transportasi umum

- Pihak pengelola Lahan Buah Condet bisa menjalin kerjasama dengan instansi terkait untuk pengadaan maupun memperbaiki sarana trasnportasi umum.

\section{Amenities (Amenitas)}

Strategi pengembangan ketiga yang digunakan untuk pengembangan Lahan Buah Condet yaitu harus memperhatikan dari segi amenitas. karena atraksi wisata agro di kawasan Condet berbeda dengan atraksi yang lain yang ada di Jakarta, serta keunggulan dari letak kawasan Condet yang strategis, maka harus didukung oleh fasilitas yang memadai guna untuk memudahkan dan memberikan kenyamanan bagi pengunjung yang datang yaitu

- Meningkatkan

kesadaran pengunjung untuk menjaga keindahan tanaman buah yang ada dengan cara menjaga kebersihan dan tidak membuang sampah sembarangan di tempat wisata.

\section{Ancillary (Fasilitas Pendukung)}

Strategi pengembangan keempat yang digunakan untuk pengembangan Lahan Buah Condet yaitu yang harus diperhatikan yakni dari segi fasilitas pendukung.

$\begin{array}{lr}\text { - Memperbaiki } & \text { fasilitas } \\ \text { keselamatan } & \text { untuk } \\ \text { meminimalisasi } & \text { bencana alam } \\ \text { salah satu ancaman berwisata di } \\ \text { sekitaran Lahan Buah Condet } \\ \text { adalah banjir. }\end{array}$

\section{Institutions (Kelembagaan)}

Pihak pengelola Lahan Buah Condet yaitu Komunitas Ciliwung Condet dapat menjalin kerjasama dengan instansi terkait guna mengembangkan potensi wisata agro di kawasan Condet Balekambang dan pengelola Lahan Buah Condet juga dapat memberdayakan masyarakat sekitar dengan memberikan penyuluhan terkait pengembangan wisata agro yang diperlukan di Lahan Buah Condet.

\section{Kesimpulan}

Berdasarkan pembahasan yang telah diuraikan sebelumnya, maka kesimpulan dari penelitian yang berjudul Pengembangan Potensi Wisata Agro di Kawasan Condet Kelurahan Balekambang Jakarta Timur yaitu, menjawab identifikasi potensi wisata agro di kawasan Condet Kelurahan Balekambang jika dilihat dari komponen pengembangan Inskeep (1991) dalam Sunaryo (2013), atraksi yang dimiliki 
oleh Lahan Buah Condet sudah cukup layak karena atraksi yang ada sudah terkait dengan seluruh faktor pertimbangan pengembangan kawasan wisata agro menurut Syamsu, (2001). Dari segi aksesibilitas menuju kawasan lahan buah Condet ini sudah cukup baik karena didukung oleh infrastruktur yang mudah karena terdapat transportasi umum sehingga memudahkan pengunjung yang ingin datang menggunakan transportasi umum, sedangkan dari segi amenitas yang terdapat di Lahan Buah Condet ini masih kurang karena keterbatasan modal dan kurangnya perhatian dari pemerintah sehingga perlu perhatian khusus dari pemerintah untuk membantu menangani masalah amenitas misalnya lahan parkir dan perawatan kebun. Untuk fasilitas pendukung pariwisata di sekitar kawasan Condet juga sudah cukup baik dan memenuhi kebutuhan pengunjung serta untuk kelembagaan sudah tersedia dan berjalan baik walaupun masih kurang dari segi administrasi dan masih belum maksimal dalam menjalankan perannya.

Untuk menjawab terkait strategi pengembangan wisata agro di kawasan Condet Kelurahan Balekambang, bahwa ditemukan beberapa aspek yang menjadi kendala pengembangan Lahan Buah Condet sebagai destinasi wisata agro seperti tidak adanya papan petunjuk yang menunjukan bahwa terdapat sebuah atraksi wisata alam yaitu kebun salak Condet, tidak adanya lahan parkir yang cukup untuk pengunjung yang datang sehingga sulit jika membawa kendaraan pribadi harus parkir di pinggir jalan atau didepan rumah warga.
Amenitas di dalam basecamp Komunitas Ciliwung Condet juga kurang memadai karena tidak ada musholla, dan fasilitas pelayanan wisata yang masih kurang serta kurang pahamnya pihak dari pemerintah dan masyarakat terhadap perkembangan pariwisata. Sehingga memunculkan rencana pengembangan potensi wisata sebagai berikut :

- Pemeliharaan konservasi alam seperti membuat program rutin bersih-bersih kebun buah Condet dan Sungai Ciliwung

- Pemerintah menyediakan fasilitas bagi pengunjung yang datang seperti tempat duduk, atau payung besar untuk berteduh jika hujan

- Pengunjung dan masyarakat diberikan edukasi mengenai pemahaman pelestarian lingkungan agar mereka sadar dan peduli akan pentingnya melestarikan lingkungan alam sekitar

- Pengelola lebih mempertegas tugas bagi para anggotanya agar manajemen pengelola dapat berjalan lebih baik lagi

\section{Saran}

Berdasarkan hasil penelitian yang dilakukan di Lahan Buah Condet yang berada di dalam kawasan Komunitas Ciliwung Condet baik dengan melakukan observasi dan wawancara pada Pemda, Komunitas Ciliwung Condet dan Tokoh Masyarakat yang masing-masing dari mereka memiliki peran pada pengembangan pariwisata di Kawasan Condet Kelurahan Balekambang. Maka diberikan saran guna pengembangan wisata agro yang lebih baik lagi. Saran yang 
peneliti berikan pada para stakeholder pariwisata di Lahan Buah Condet antara lain:

1. Pemerintah dan Komunitas Ciliwung Condet harus memperbaiki komunikasi mereka guna kebaikan bersama karena melalui Komunitas suara masyarakat dapat disampaikan ke Pemerintah,

2. Pemerintah harus lebih sering mengupdate perkembangan Lahan Buah Condet sebagai daya tarik wisata di Condet agar dapat mengetahui apa kekurangan yang harus diselesaikan seperti pembangunan Tourism Information Centre (TIC), lahan parkir, toilet umum serta amenitas lainnya,

3. Pemerintah bersama Komunitas harus memberikan sosialisasi dan penyuluhan pada masyarakat sekitar terkait pariwisata khususnya wisata agro sehingga kedepannya masyarakat dapat mandiri dalam mengembangkan wisata di lahan buah Condet dengan konsep wisata agro,

4. Komunitas selaku pengelola di lapangan harus lebih sering mengikutsertakan masyarakat sekitar dalam pengelolaan wisata dan mengajak mereka berpartisipasi dalam pengembangan pariwisata di kawasan Condet

5. Masyarakat harus lebih peduli pada kondisi lingkungan sekitar apabila ingin daerah mereka ramai dikunjungi wisatawan. Masyarakat dilarang membuang sampah sembarangan di Sungai
Ciliwung yang menyebabkan banjir. Sehingga jika terjadi banjir maka Lahan Buah Condet akan terendam banjir dan akan gagal panen.

\section{DAFTAR PUSTAKA}

Amalia, A. 2016. Peran Komunitas Ciliwung Condet Sebagai Aktor Gerakan Lingkungan Untuk Masyarakat Sekitar [Skripsi]. Jakarta (ID): Universitas Negeri Jakarta

Kodir, A. 1994. Kajian Sosial Ekonomi Masyarakat Petani di Perkotaan Studi Kasus di wilayah Cagar Budaya Lahan Buah Condet Kecamatan Kramat Jati Jakarta Timur.[Skirpsi]. Jakarta (ID): Universitas Borobudur

Miles, M.B, Michael H. 1992. Analisis Data Kualitatif: Buku Sumber Tentang Metode-metode Baru. Jakarta (ID): UI Press

Nanda, F.F, Wulandari L.D, Ramdlani S dkk. 2017. Konsep Agrowisata pada Lahan Konservasi Studi Kasus: Lahan Buah Condet, Jakarta Timur. Jakarta (ID). Jurnal Mahasiswa Jurusan Arsitektur .Universitas Brawijaya Malang

Spillane, J. 1994. Pariwisata Indonesia (Siasat Ekonomi dan Rekayasa Kebudayaan). Yogyakarta (ID) : Kanisius. 
Widihastuti, K. 2004. Peranserta

Masyarakat Dalam

Pengelolaan Lingkungan

Kawasan Condet Untuk

Pengembangan Potensi

Wisata Agro [Tesis]. Depok

(ID): Universitas Indonesia

Yoharman, S. 2001. Puslitdimas STP

Trisakti. Jakarta (ID): Bintara 